\title{
MULTILETRAMENTOS NA ERA DIGITAL UMA REFLEXÃO CRÍTICA PARA A EDUCAÇÃO
}

\author{
Clara Vaz Bauler é aluna de doutorado e membro docente da Escola de Formação de Professores da Universidade da Califórnia, Santa \\ Barbara \\ E-mail: cbauler@education.ucsb.edu
}

\begin{abstract}
Resumo
O presente artigo visa a discutir a relação entre o advento de multiletramentos digitais e seus desdobramentos em práticas de escrita e leitura em ambientes virtuais na área de educação. Dentro de uma perspectiva sócio-cultural e histórica do discurso, procurar-se-á enfatizar a questão de que as práticas sociais e comunidades com que as pessoas convivem e interagem, estão intimamente relacionadas aos tipos de letramento a que elas têm acesso, principalmente se se consideram novas exigências de uma era de globalização e o capitalismo rápido. Nesse sentido, a difusão dos letramentos digitais na Internet possibilitou a construção de outros significados e modos de escrever e ler em nossa sociedade. Por outro lado, com a valorização dos letramentos digitais desenvolveram-se desigualdades cada vez mais profundas entre os indivíduos que se envolvem nessas práticas letradas e aqueles que permanecem alijados, sem acesso e sem voz na era digital. Nesse contexto, estar conectado ao mundo virtual torna-se uma questão fundamental na atualidade.
\end{abstract}

\begin{abstract}
This article aims to discuss the relationship between the -emergence of multiliteracies, including its many forms of reading and writing on the Internet, and education. Within a sociocultural and historical perspective of discourse, I intend to focus on the fact that the social practices and communities in which people live and interact are closely related to the kinds of literacy to which they have access. From this perspective, on the one hand, the emergence of digital literacies on the World Wide Web provided the means to construct different meanings and ways of doing and being in our society. On the other hand, the valorization of digital literacies brought great disparities between those who are engaged in digital literacy practices and those who do not have access to these same practices, remaining voiceless and apart from the whole process of participating actively in socially valued practices In this context, to engage in digital literacy practices is a really relevant issue in our era.
\end{abstract}

\section{Introdução}

$\mathrm{O}$ advento da Internet vem transformando o modo com que as pessoas se relacionam com os atos de escrever e ler, tanto no âmbito profissional, como na esfera pessoal. Mandar e-mails, trocar mensagens no Facebook e ler o jornal diário em sua versão virtual são algumas das atividades frequentes na vida de milhões de habitantes de nosso planeta. Nessa perspectiva, as práticas sociais e as comunidades com que os interlocutores convivem e interagem estão intimamente relacionadas aos tipos de letramento a que essas pessoas terão acesso.

Apesar da euforia com que muitos se referem e participam em atividades no meio virtual, à medida que usuários desfrutam dos prazeres de estarem conectados ao mundo cibernético, desigualdades profundas entre os indivíduos que se envolvem em práticas 
letradas no mundo virtual e aqueles que permanecem confinados às suas vidas locais, sem contato e sem voz num mundo "globalizado" (Bauman, 1998), se intensificam.

Essa situação revela que o surgimento de multiletramentos que se utilizam de meios digitais para serem difundidos contribuiu para o surgimento de novos modos de agir no mundo por meio da linguagem. Como resultado, escrever e ler na Internet requer familiaridade com uma série de novas habilidades e conhecimentos que envolve engajamento com novas tecnologias e práticas culturais. A difusão do conhecimento e de discursos na Internet possibilitou a construção de outros significados que podem ser interpretados como um desafio para aqueles que não se conectam ao mundo virtual com tanta frequência (Gee, 2010).

Nesse contexto, a escola se apresenta como uma alternativa em que essas habilidades e conhecimentos poderiam ser desenvolvidos (Collins e Halverson, 2009). Em vista dessa ideia, o presente trabalho visa a discutir a relação entre os multiletramentos multimodais da era virtual e globalizada e sua relevância para práticas educativas. Para tanto, este trabalho adotará uma perspectiva sociointeracional e histórica do discurso e suas realizações em muitos modos de ler e escrever na Internet. Consequentemente, este trabalho visa também a refletir sobre as possíveis consequências e impacto do ato de escrever e ler na Internet na área da educação, de modo a fazer uma reflexão crítica do acesso aos letramentos e da condição de estar ou não conectado e inserido em um mundo digital e global.

\section{Situando Historicamente: A Era Digital e Globalizada}

Em Modernização Reflexiva, Beck, Giddens e Lash (1997) desenvolvem a ideia de que a ordem social moderna é marcada pela reflexividade, pela destradicionalização, pela ecologia e pelo risco. Esse estado de coisas teve início com a queda do Muro de Berlim, em 1989, em que se passou a questionar e desafiar as bases do sistema sociopolítico ocidental, bem como a eficácia do capitalismo e da democracia.

O ocidente é confrontado por questões que desafiam as premissas fundamentais do seu próprio sistema social e político. A principal questão que ora enfrentamos é se a simbiose histórica entre capitalismo e democracia - que caracterizava o Ocidente - pode ser generalizada em uma escala global, sem consumir suas bases físicas, culturais e sociais. (Beck, 1997, p. 11)

Para Beck (1997), a modernização reflexiva significa a possibilidade de uma "(auto)destruição criativa" da velha sociedade industrial, fazendo surgir a reincorporação de novos conceitos e possibilitando a formação de uma nova modernidade. Isso significa que a sociedade está se reinventando, não de forma revolucionária, mas de forma 
silenciosa, com as transformações tecnológicas, o crescimento econômico, as novas leis de flexibilização trabalhista e outras mudanças sociais, como a inclusão da mulher no mercado de trabalho.

Este novo estágio, em que o progresso pode se transformar em autodestruição, em que um tipo de modernização destrói outro e o modifica, é o que eu chamo de etapa da modernização reflexiva. (Beck, 1997, p. 12)

Dentre as características fundamentais do processo de modernização reflexiva está a reflexividade, que se refere ao poder de negociação, à crítica ativa, à pluralidade de vozes que ora se ouvem nos muitos repertórios discursivos circulantes, especialmente nos países ricos do primeiro mundo. Os indivíduos e comunidades ganham voz e passam a questionar os valores e bases da Velha Ordem, em que as esferas políticas ortodoxas eram as únicas a tomar decisões (Beck, 1997; Beck, Giddens e Lash, 1997). Hoje é possível vislumbrar a participação, ainda que minoritária, de outros grupos, como mulheres, negros, gays, outrora marginalizados, nas discussões que envolvem soluções para problemas políticos, econômicos e sociais.

Todavia, ao mesmo tempo em que as pessoas ganham voz ativa e se tornam mais participantes de questões fundamentais, é colocada uma grande responsabilidade no indivíduo, que passa a "produzir, representar e acomodar suas próprias biografias" (Beck, 1997, p. 24). Isso significa que o indivíduo, em nome de um status social mais elevado e do bem estar social (welfare state), é responsável por "operar e persistir como agente individual e planejador de sua própria biografia” (Beck 1997, p. 27): não há um modelo de mulher ou homem, mas vários modelos. Beck denomina esse fenômeno de individualização. Nesse quadro, as decisões políticas e as instituições se tornam cada vez mais dependentes do indivíduo:

Por um lado, está se desenvolvendo um vazio político das instituições: por outro, um renascimento não institucional do político. $\mathrm{O}$ sujeito individual retorna às instituições da sociedade. (Beck, 1997, p. 28)

Ainda nessa perspectiva, a clareza das instituições e partidos políticos, tão acentuada na Velha Ordem, dividida em dicotomias tão evidentes, como direita e esquerda, liberal e conservador, socialista e capitalista, cai por terra.

...surge um engajamento múltiplo contraditório, que mistura e combina os pólos clássicos da política de forma que, se pensarmos nas coisas em relação à sua conclusão lógica, todo mundo pensa e age como um direitista ou um esquerdista, de maneira radical ou conservadora (...) Todos são pessimistas, pacifistas, idealistas, ativistas em aspectos parciais 
do seu ser. Entretanto, isso só significa que as clarezas atuais da política (...) não são mais corretas ou efetivas. (Beck, 1997, p. 33)

Para Gee (2000) e Gee e Lankshear (1997), outra questão emerge da individualização, o surgimento de um novo ser: "a pessoa portifólio". Isso significa que a nova ordem de trabalho, caracterizada pela falta de hierarquia e por parceiros que atuam no mesmo local de trabalho, em comunidades de prática (Lave e Wenger, 1991), que se engajam em uma tarefa significativa em um ambiente de colaboração (Lankshear e Gee, 1997), exige um novo tipo de trabalhador. Logo, surge um novo indivíduo "motivado" que não é mais comandado, mas trabalha em grupos de maneira a administrar independentemente suas tarefas.

Nesse contexto, o novo tipo de trabalhador "portifólio", exigido pelo mercado, deve se adaptar a todo o momento às novas tendências e necessidades dos projetos em que se envolve. De outra forma, ele se tornará totalmente inútil. Deve-se ressaltar que esse novo estado de coisas não é colocado de maneira voluntária. Os indivíduos não escolhem essa condição de individualização (Beck, 1997, p. 26).

Para Gee (2000), duas pessoas emergem, então, desse novo capitalismo: uma que se enquadra nas exigências, a portifólio, e a outra que fica à margem. Para evitar essa possivel discrepância entre dois tipos de trabalhadores, Gee e Lankshear (1997) sugerem mudanças ligadas a linguagens e letramentos a que os indivíduos tenham acesso. A escola poderia ser uma instituição que promoveria práticas educacionais em que o acesso a letramentos valorizados pela sociedade, incluindo os mediados pelo computador e Internet, seria possibilitado a todos os tipos de trabalhadores, não só o portfólio. Nesse sentido, a educação se voltaria a desenvolver um conhecimento crítico da língua, especialmente do vocabulário específico das tarefas pertencentes ao capitalismo rápido, para que se possa lutar por melhores condições de trabalho (Gee, 2000; Gee e Lankshear, 1997).

Como explicado acima, esse conhecimento crítico da linguagem advém das práticas de letramento em que os indivíduos se engajam. Como resultado, aqueles que não possuem o tipo de conhecimento exigido pela sociedade globalizada e pelo capitalismo rápido (Beck, Giddens e Lash, 1997) se encontram fora do mercado de trabalho e fora das benesses da vida digital e globalizada, não participando de embates discursivos e não fazendo ouvir suas vozes. Nesse contexto, o conhecimento se torna o bem mais valorizado na sociedade contemporânea (Gee, 2000).

Em face dessa nova ordem, atormentada pelo risco, com grandes inovações tecnológicas e formada por indivíduos construídos "através de uma interação discursiva complexa" (Beck, 1997: 28), é possível concluir que muitos são alijados desse progresso e não poderão fazer-se ouvir, mesmo em uma sociedade em fase de reflexão e debate (Bauman, 1998). Nesse contexto, o mundo digital e globalizado não se tornaria tão 
admirável quanto poderia ser, pois não proporciona as mesmas oportunidades a todos que nele vivem, apesar de seus ideais democráticos e igualitários.

\section{Multiletramentos e Letramentos Digitais: Uma Nova Concepção}

Por muito tempo, o letramento foi considerado uma habilidade desenvolvida pelo leitor cognitivamente no ato da leitura. Em uma perspectiva tradicional, adotada por práticas educacionais mais convencionais, o letramento é entendido como uma atividade individual de decodificação, um processo perceptivo e cognitivo apenas, sem levar em consideração os aspectos interacionais e sociais. O significado, nessa perspectiva mais tradicional, é tido, então, como logocêntrico, advindo somente do texto (Soares, 2004).

Atualmente, contrário a teorias mais tradicionais, novas ideias pautadas na concepção de que os seres humanos utilizam a linguagem para construir significados discursivamente num ambiente marcado por características sociais, culturais e históricas, consideram o letramento uma prática social (Barton e Hamilton, 1998; Green et alii, 1994; Cope e Kalantzis, 2000; Moita Lopes, no prelo). Isso significa que o letramento é um processo dinâmico, construído socialmente em um determinado tempo e cultura. Dentro dessa perspectiva, não se deve mais falar em letramento e sim em letramentos (no plural) ou multiletramentos (Cf. Green et alli, 1994; Barton e Hamilton, 1998; Lankshear e Knobel, 2008), pois a cada prática social de letramento em que o indivíduo se engaja (como a sala de aula, a compra de um produto, a ida à igreja), constroem-se outros significados por meio da linguagem e, dessa forma, se definem e se transformam os próprios letramentos e as identidades dos participantes da interação. Nessa perspectiva, os letramentos estão associados aos diferentes domínios da vida (Barton e Hamilton, 1998).

Ademais, é importante ressaltar que em uma sociedade altamente semiotizada, há muitas e variadas formas de construção de significado, ligando a concepção de texto não só ao escrito, mas também ao visual, auditivo, perceptivo, comportamental, etc. (Barton e Hamilton, 1998). Sendo o significado multimodal, ou seja, composto de variadas realizações, incluindo imagens e sons, os letramentos não podem ser confinados ao "mero letramento" (Barton e Hamilton, 1998), centrado apenas nos aspectos verbais e veiculado apenas em uma língua padrão. Daí a relevância que ganham outros letramentos, como os computacionais, especialmente valorizados pela era digital e virtual.

Além dos aspectos formais, teorias recentes (Cope e Kalazantzis, 2000; Gee, 2010) enfatizam a ideia de que os letramentos devem incluir não só aspectos multimodais da construção do significado, mas devem considerar também os aspectos culturais, que abarcam um conceito de língua mais abrangente, em que a língua padrão não é o único 
registro utilizado, mas um dentre muitos de que o falante dispõe, como, por exemplo, o registro familiar, o informal e até a utilização de outras línguas não hegemônicas.

Desse modo, sendo os significados construídos socialmente e as posições sociais que as pessoas ocupam no mundo determinadas pelos embates discursivos travados nessa construção social dos significados (Moita Lopes, 1996), as práticas de letramento são muitas vezes institucionalizadas por quem tem mais poder na sociedade, ou seja, por quem, no embate da construção dos significados, é considerado o detentor dos discursos mais corretos e valorizados pela sociedade (Barton e Hamilton, 1998; Aronowitz e Giroux, 1991). Consequentemente, alguns tipos de letramento serão mais dominantes e influentes que outros. Esse é o caso do letramento provido pela escola. Nessa perspectiva, é importante se ater ao que conta como letramento para cada comunidade, indivíduo ou instituição (Green et alii, 1994) a fim de que se analise mais acuradamente em que tipo de prática letrada as pessoas estão se envolvendo, que tipo de relação elas mantêm umas com as outras e como elas se engajam com o texto (Green et alii, 1994).

Outra questão importante é a relação entre letramentos e comunidades ou redes interpretativas. Sendo os letramentos práticas sociais construídas, definidas e redefinidas dentro e por diferentes grupos (Green et alii, 1994), os significados passam a ser considerados "propriedades de comunidades interpretativas que são responsáveis tanto pela forma das atividades do leitor quanto pelos textos que estas atividades produzem" (Fish, 1993, p. 156). Isso significa que mais uma vez deve ser considerado o que conta como letramento para dada comunidade e que textos são, assim, valorizados ou rejeitados por ela.

$\mathrm{Na}$ atualidade, a Internet é um espaço bastante profícuo na formação de redes e comunidades interpretativas. Por meio de variados gêneros emergentes, devido ao suporte computacional, como os chats, as comunidades do tipo Facebook, Orkut, Twitter, Messenger, blogs etc., e de outros tipos de texto, como o hipertexto da Wikipedia ou os comentários de vídeo e reportagens que se encontram no website Youtube e em reportagens publicadas em jornais virtuais, os internautas se engajam em embates discursivos e conversam sobre textos.

Além da Internet, a televisão e outros veículos midiáticos também contribuem para discussões virtuais, alargando os espaços de construção de significados e, consequentemente, de letramentos bastante relevantes na sociedade atual. No Brasil, formam-se comunidades interpretativas em torno de assuntos preferidos no país, como futebol e telenovela, por exemplo. Muitas pessoas se reúnem em bares e nas ruas para comentar o que aconteceu com os personagens da novela ou para discutir a melhor jogada de Ronaldinho Gaúcho. Essas conversas, que outrora ficariam confinadas às ruas e espaços "reais" em que a presença física é uma constante, agora também se realizam nos ambientes virtuais do Facebook, por exemplo. Todos os times populares cariocas, como Flamengo, 
Fluminense, Botafogo e Vasco, possuem uma página dedicada a fãs que podem fazer comentários e receber notícias de seus times favoritos. Ė interessante frisar que ao comentar e receber notícias, fãs de futebol estão se engajando em práticas emergentes de letramento no meio virtual. Comentários e notícias se realizam na forma escrita, proporcionando aos participantes novas formas de ler e escrever através da Internet.

Nesse contexto, os letramentos devem ser entendidos como práticas sociais em que os indivíduos se engajam cotidianamente por meio de comunidades interpretativas, instituições e outros modos de agir discursivamente através da linguagem. Devido à sua natureza social e variada, os letramentos devem ser considerados em suas multimodalidades, incluindo aí não só o texto escrito, mas todas as formas semióticas de construção de significado.

\section{Multiletramentos e educação: um desafio}

A escola geralmente prioriza um único tipo de letramento, o modelo autônomo de letramento (Street, 1995; 1993), sem considerar os muitos outros inseridos em práticas sociais diversas, inclusive os que ocorrem na própria escola, como as conversas no recreio, compras de lanche na cantina e algumas realizações de tarefas em grupo. O chamado modelo autônomo de letramento, em que os aspectos técnicos da língua são estudados independentemente de seus contextos sociais, se opõe ao modelo ideológico de letramento, em que as práticas de letramento estão intrinsecamente ligadas a estruturas culturais e de poder em uma dada sociedade (Street, 1995).

O modelo ideológico de letramento, ao contrário do modelo autônomo, se aproxima de uma visão sociointeracional e histórica do discurso e de uma perspectiva dialógica da linguagem ao considerar que os seres humanos são construídos discursivamente nas relações de poder da sociedade. Os letramentos não são neutros, como advoga o modelo autônomo.

Além da concepção de modelo autônomo de letramento, a escola tende a considerar a oralidade separadamente da escrita, divisão tão criticada por muitos linguistas e antropólogos (Street, 1995, Barton e Hamilton, 1998; Kleiman, 1995). Em muitos eventos de letramento, existe uma mistura entre língua escrita e falada (Barton e Hamilton, 1998). Ademais, é muito comum, nas várias práticas sociais, a conversa sobre textos, o que se pode notar num papo de botequim sobre uma notícia de jornal.

A escola ainda confunde os conceitos de letramento e alfabetização, considerando o letramento como uma simples atividade de decodificação de significados logocêntricos. Alfabetizar significa apenas adquirir a tecnologia do ler e escrever (Soares, 2004) e não a noção do que se faz na sociedade com essa tecnologia, ou seja, em que práticas e eventos 
sociais a pessoa se engaja ao ler e escrever, construindo e fazendo circular discursivamente os significados, como é o caso dos letramentos.

Ademais, a escola apóia a crença de que o letramento é a "salvação para os analfabetos". Ensinar a ler libertaria o indivíduo da sua ignorância, é o chamado mito do letramento (Graff, 1994 e Signorini, 1994a; 1994b). O simples fato de adquirir a "letra" não muda a situação de exclusão social em que se encontra um indivíduo que não participa de outras práticas letradas e, principalmente, que não tem acesso a práticas letradas privilegiadas pela sociedade. Hoje, os letramentos computacionais e de língua estrangeira para comunicação com variadas pessoas que vivem e trabalham em outros locais do planeta são os mais valorizados. Em relatório recente, publicado em janeiro de 2011, a associação "Partnership for 21st Century Learning Skills" (www.P21.org) revela que parte integral das habilidades requeridas para obter sucesso no século XXI está a capacidade de compreender e se comunicar com pessoas de múltiplas culturas tanto no ambiente de trabalho e no pessoal, e isso se dará através de conexões globais por meio da Internet.

Por tudo isso, a escola, em geral, ignora que os letramentos são práticas sociais em que os significados são construídos discursivamente de múltiplas formas entre indivíduos, num dado momento histórico, em batalhas travadas por relações de poder. Dessa forma, as aulas de letramento ocorrem em um vácuo social, distanciando os alunos das outras práticas em que eles se engajam no seu cotidiano. Ademais, o tratamento dado pela escola aos letramentos computacionais, tão em voga na atualidade, está longe de ser prioritário (Collins e Halverson, 2009). Para Lankshear e Knobel (1997a, p. 133), “...as escolas não estão em contato com os letramentos tecnológicos emergentes" e, dessa forma, se distanciam da realidade cotidiana dos alunos que possuem computadores e lidam com os significados construídos nesse suporte diariamente.

É importante notar que Lankshear e Knobel se reportam à Austrália e no ano de 1997, ou seja, há quase quinze anos atrás. No Brasil, a realidade pode ser ainda mais preocupante, pois a grande maioria dos estudantes ainda não tem acesso a computadores e, especialmente, à Internet, lugar dos embates discursivos e discussões virtuais. Segundo um estudo relativamente recente, conduzido em 2007 pelo pesquisador da UNESCO Julio Jacob Waiselfisz, no Brasil, entre os $10 \%$ mais pobres, apenas 0,6\% tem acesso a computador com Internet, entre os $10 \%$ mais ricos esse número é de 56,3\%. O mesmo estudo revelou que no ensino fundamental, apenas 17,2\% dos alunos das escolas públicas usam a Internet, ao passo que, nas escolas particulares, esse número sobe para 74,3\%. Esses números sugerem alarmante desigualdade no que concerne à tão sonhada inclusão digital para todos, de modo a ainda perpetuar insistentes discrepâncias sociais que tanto marcam a nossa sociedade. 
Nesse contexto, inserir outros letramentos em práticas educacionais, principalmente os computacionais, se torna fundamental na intenção de se minimizar os processos de exclusão em uma sociedade em que o conhecimento se tornou moeda de valor e de troca. $\mathrm{O}$ computador e, por conseguinte, a Internet, têm gerado inúmeros outros meios de agir no mundo discursivamente por meio da linguagem. A escola não pode ignorar que o advento da Internet proporcionou aos indivíduos um novo modo de agir no mundo através da linguagem. Dentro de uma perspectiva em que se tornar letrado é aprender o que conta como letramento para determinada comunidade, grupo ou sociedade (Moita Lopes, no prelo), engajar-se em uma prática de letramento é uma forma de agir no mundo por meio da linguagem (Freire e Macedo, 1987).

Ainda nesse sentido, tornar-se parte do mundo virtual é participar de práticas sociais de letramento mediadas por tecnologias eletrônicas. Letramentos virtuais ou tecnológicos serão considerados aqui, no entendimento de Lankshear e Knobel (1997a), o seguinte: práticas sociais em que textos são construídos, transmitidos, recebidos, modificados, compartilhados e engajados, por um processo de codificação eletrônica, primeiramente, mas não exclusivamente por meio de microcomputadores, envolvendo também vídeo games, tabletes, MP3 players etc. Ao se engajarem em práticas sociais de letramento tecnológico, alunos têm oportunidade de dispor de um novo espaço para se construir e se redefinir - a 'realidade' virtual. Principalmente, com as exigências de um mundo globalizado, como discutido acima, crianças e adolescentes em idade escolar podem começar a desenvolver capacidades que vão ajudá-los a participar ativamente em atividades de ler e escrever valorizadas pela sociedade.

Para ilustrar a impotância do desenvolvimento e adoção de letramentos digitais em práticas educacionais, em reportagem de 11 de janeiro de 2006, a Revista Veja publicou a seguinte matéria: "A vitrine do candidato: empresas adotam a prática de espionar no Orkut a vida pessoal dos que buscam uma vaga", trazendo várias 'dicas' de como se comportar nessa comunidade virtual para a pessoa que está procurando emprego. As sugestões incluem: não "participar de comunidades do tipo "Eu odeio" e "ter uma ampla rede de amigos. Isso mostra sociabilidade". Isso significa que a empresa, ao contratar um candidato, leva hoje também em consideração as práticas sociais em que ele ou ela se engaja na realidade virtual. $\mathrm{O}$ modo como a pessoa age discursivamente no espaço cibernético, passou a ser fator diferencial na aquisição de um emprego.

É fácil vislumbrar que, em meio às inovações da tecnologia eletrônica e da proliferação da utilização do espaço virtual, muitos indivíduos ainda se encontram marginalizados nesse processo. Muitos brasileiros não possuem computador e muitos nunca acessaram a Internet. Nesse contexto, ser ou não virtual passaria a ser uma necessidade, pois aqueles que participam de práticas de letramento tecnológico estariam mais integrados 
ao mundo globalizado e seriam menos expostos à exploração na nova ordem do trabalho (Bauman, 1998). As fronteiras entre o mundo virtual e o real se tornam cada vez menos delimitadas, ao mesmo tempo em que enormes fossos se erigem entre o mundo da globalização e o mundo da exclusão (Bauman, 2004).

A fim de minimizar esse problema, educadores propõem algumas soluções: a) desenvolver uma linguagem crítica, avaliando e analisando os conceitos e discursos circulantes na atualidade, fazendo da sala de aula um verdadeiro laboratório de linguística e tornando os alunos cientes do seu papel de agentes transformadores da história e da sociedade (Cope e Kalazantzis, 2000; Gee, 2000; Gee e Lankshear, 1997; Fecho, 1998; Aronowitz e Giroux, 1991); b) ainda nessa perspectiva, trazer textos diferentes dos chamados cânones e discutir outros conceitos que não sejam os hegemônicos, ou seja, promover debates e analisar textos sobre a mulher na sociedade, questões de raça e sexualidade, a fim de que os alunos lutem contra as verdades únicas dominantes e desconstruam conceitos arraigados, para que, assim, mudem a sociedade (Fecho, 1998; Gilbert, 1997; Batista e Galvão, 1999; Moll, 1994; Moita Lopes, 2002); c) Falar sobre os textos, conversar, debater, para que as vozes dos alunos também sejam ouvidas (Maybin e Moss, 1993; Lemke, 1989); d) tratar a leitura como evento social e não como atividade de simples decodificação (Moita Lopes, 1995; 1996; Bloome, 1993); e) se ater a outros eventos de letramento que não os hegemônicos e privilegiados pela escola e, assim, valorizar os letramentos que os alunos têm acesso em seu ambiente familiar e fora da escola (Heath, 1994; Moll, 1994); f) trabalhar a intertextualidade e a interdisciplinaridade de modo a formar um leitor consciente dos vários discursos e domínios discursivos e fazê-lo agir no mundo social por meio da linguagem nas práticas sociais em que se envolve (Moita Lopes, 1996; Bloome e Bailey, 1992).

Ainda em relação a práticas educativas, possibilidades de uso de formas emergentes de multiletramentos digitais são infinitas. Páginas de Facebook podem ser usadas para compartilhar e refletir sobre tópicos abordados em sala de aula de modo a estimular um ambiente mais participativo para os estudantes (Jenkins, 2009; Gee, 2010). O hipertexto encontrado em websites educacionais e informativos como a Wikipedia, por exemplo, poderia ser um modo diferente de trabalhar os textos e enriquecer os repertórios discursivos a que alunos têm acesso. Alunos podem colaborar uns com os outros para construir enciclopédias virtuais, utilizando-se de pesquisas e conteúdo criado pelos próprios alunos. Todavia, é uma prática que exige formação e experiência dos professores para lidar com alunos que nunca tiveram contato com esse tipo de texto (Marcuschi, 1999; Foltz, 1996). Daí um outro problema decorre, a falta de investimento na formação de professores críticos e preparados para lidar com variados tipos de letramento, inclusive os digitais. 
Desse modo, a escola precisa mudar a sua concepção de letramento para que possa oferecer oportunidades reais para indivíduos e comunidades que se encontram à margem da sociedade globalizada. A escola precisa se engajar em outras práticas sociais letradas, de modo a inserir as formas multimodais de construção de significado da atualidade, conscientizar os alunos dos embates discursivos e das relações de poder e, assim, formar agentes ativos e participantes na mudança do futuro da sociedade (Cope e Kalantzis, 2000).

\section{Conclusão}

Como sabiamente apontado pelos educadores Collins e Halverson (2009), se a escola não começar a adotar uma política séria de inserção de práticas de letramentos digitais bem como de desenvolvimento de capacidades, habilidades e conhecimentos para a participação efetiva nessas práticas, os aprendizados mais valorizados socialmente deixarão a escola para trás. Entretanto, se a escola adotar uma política de acesso aos multiletramentos digitais, poderá possibilitar aos alunos a participação ativa nos embates discursivos da atualidade, proporcionando o que Gee (2000) chama de Carta Magna (Bill of Rights) da educação, ou seja, a luta por direitos mais igualitários para todos. Práticas educacionais sugeridas por Gee e colegas não só possibilitariam a inserção de indivíduos no mercado de trabalho, mas também facilitariam a preparação para o conhecimento crítico da linguagem através das variadas práticas de letramento em que os indivíduos se engajariam. A participação em embates discursivos em esferas públicas na Internet, como conversas em redes sociais e discussões em fóruns de leitores motivados por reportagens jornalísticas em web sites e blogs, agem de forma a promover a conscientização (Freire, 1968 e 1996) e a incluir mais pessoas em diálogos importantes na sociedade.

Em um mundo globalizado, digital e de capitalismo rápido, o engajamento em práticas sociais diferenciadas de letramento, incluindo aí os mediados por tecnologias eletrônicas, se impõem como uma realidade inescapável em uma política de inclusão. Nesse sentido, a missão fundamental da educação é, então, prover oportunidades para os alunos, alargando seus repertórios de letramentos e ajudando-os a agir discursivamente e criticamente na mudança do futuro. Nessa perspectiva, a inclusão digital e o engajamento em múltiplas práticas de letramento virtual pode ser um caminho para a transformação social.

\section{Referências Bibliográficas}


ARONOWITZ, S.; GIROUX, H. Cultural politics, reading formation and the role of teachers as public intellectuals. In: ARONOWITZ, S.; GIROUX, H. Postmodern education. Minneapolis: University of Minnesota Press, 1991.

BARTON, D.; HAMILTON, M. Local literacies: reading and writing in one community. London: Routledge, 1998.

BATISTA, A. A. G.; GALVÃO, A. M. Práticas de leitura, impressos e letramentos: uma introdução. In: BATISTA, A. A. G. e GALVÃO, A. M. (orgs.). Leitura: práticas, impressos e letramentos. Belo Horizonte: Autêntica, 1999.

BAUMAN, Z. Globalization: the human consequences. United Kingdom: The Polity Press, 1998.

Wasted lives: modernity and its outcasts. USA: Polity Press, 2004.

BECK, U.; GIDDENS, A.; LASH, S. Modernização reflexiva. São Paulo: Unesp, 1997.

BLOOME, D. Necessary indeterminancy and the microethnography study of reading as a social process. Jornal of Research in Reading, 16 (2), 1993. P. 98-111.

; BAILEY, F. M. Studying language and literacy through events, particularity, and intertextuality. In: BEACH, R., GREEN, J., KAMIL, M.; SHANAHAN, T. (eds.). Multiple disciplinary perspectives on literacy research. Urbana, II: NCRE: NCTE, 1992.

COLLINS, A.; HALVERSON, R. Rethinking education in the age of technology: the digital revolution and schooling in America. New York: Teachers College Press, 2009.

COPE, B.; KALANTZIS, M. Introduction: multiliteracies: the beginning of an idea. In: . (eds.). Multiliteracies, literacy,learning and the design of social futures. London: Routledge, 2000.

FECHO, B. Crossing boundaries of race in a critical literacy classroom. In: ALVERMANN, D. E. et alii. (eds.). Reconceptualizing the literacies in adolescents' lives. Mahwak, NJ: Lawrence Erlbaum, 1998.

FISH, S. Como reconhecer um poema ao vê-lo. Palavra, 1, 1993. P. 156-165.

FOLTZ, P. W. Comprehension, coherence and strategies in hypertext and linear text. In: ROUET, J. F., LEVONEN, J. L., DILlON, A.; SPIRO, R. J. (eds.). Hypertext and cognition. Mahwak: New Jersey.

FREIRE, P. Pedagogia do oprimido. Rio de Janeiro: Paz e Terra, 2005. (Trabalho original publicado em 1968.) 
Pedagogia da autonomia. Rio de Janeiro: Paz e Terra, 1996.

FREIRE, P.; MACEDO, D. Literacy: reading the word and the world. New York: Bergin: Garvin, 1987.

GEE, J. P. New digital media and learning as an emerging area and "worked examples" as one way forward. The John D. and Catherine T. MacArthur Foundation; MIT Press, 2010.

. New people in new worlds: networks, the new capitalism ans schools. In: COPE, B.; KALANTZIS, M. (eds.). Multiliteracies, literacy,learning and the design of social futures. London: Routledge, 2000.

GILBERT, P. Discources on gender and literacy: changing the stories. In: MUSPRATT, S., LUKE, A., FREEBODY, P. (eds.). Construction critical literacies. Cresskill, NJ: Hampton Press, Inc., 1997.

GINSBURG, C. O queijo e os vermes. São Paulo: Cia. das Letras, 1987.

GRAFF, H. The legacies of literacy. In: MAYBIN, J. (ed.). Language and literacy in social practice. Clevendon: Multilingual Matters, 1994.

GREEN et alii. Constructing literacy in classrooms: literate action as social accomplishment. In: RUDDELL, B., RUDDELL, M. R.; SINGER, H. (eds.). Theoretical models and processes of reading. New York: International Reading Association, Inc, 1994.

HEATH, B. S. What no bedtime story means: narrative skills at home and at school. In: MAYBIN, J. (ed.). Language and literacy in social practice. Clevendon: Multilingual Matters, 1994.

JENKINS, H. Confronting the challenges of participatory culture: media education for the $21^{\text {st }}$ century. The John D. and Catherine T. MacArthur Foundation; MIT Press, 2009.

KLEIMAN, A. Modelos de letramento e as práticas de alfabetização na escola. In:

(org.). Os significados do letramento. Campinas: Mercado das Letras, 1995.

LANKSHEAR, C.; GEE, J. P. Language literacy and the new work order. In: LANKSHEAR, C. Changing literacies. Buckingham: Open U Press, 1997.

LANKSHEAR, C.; KNOBEL, M. Literacy, texts and difference in the eletronic age. In: LANKSHEAR, C. Changing literacies. Buckingham: Open U Press, 1997a. 
Different worlds? Technology-mediated classroom learning and students social practices with new Technologies in home and community settings. In: LANKSHEAR, C. Changing literacies. Buckingham: Open U Press, 1997b.

M. Introduction: Digital Literacies - Concepts, Policies and Practices. In Colin Lankshear: Michelle Knobel (Eds.). Digital literacies: concepts, policies and practices. New York: Peter Lang, 2008.

LAVE, J.; WENGER, E. Situated learning: legitimate peripheral participation. Cambridge: Cambridge University Press, 1991.

LEMKE, J. L. Making text talk. Theory into practice, 28 (2), 1989. P. 136-141.

LUKE, C. Media, literacy and cultural studies. In: MUSPRATT, S., LUKE, A., FREEBODY, P. (eds.). Construction critical literacies. Cresskill, NJ: Hampton Press, Inc., 1997.

MARCUSCHI, L. A. Linearização, cognição e referência: o desafio do hipertexto. IV colóquio da Associação Latino-americana de Analistas do Discurso. Santiago do Chile, mimeo, 1999.

MAYBIN, J.; MOSS, G. Talk about texts: reading as a social event. Journal of Research in Reading, 16 (2), 1993. P. 138-147.

MOITA LOPES, L. P. What is this class about? Topic formulation in an L1 reading comprehension classroom. In: COOK, G.; SEIDLHOFER, B. (eds.). Principle and practice in applied linguistics. Oxford: Oxford University Press, 1995.

Interdisciplinaridade e intertextualidade: leitura como prática social. Anais do III Seminário da Sociedade Internacional Português Língua Estrangeira. UFF, Niterói, 1996.

Identidades fragmentadas. Campinas: Mercado das Letras, 2002.

A construção do gênero e do letramento na escola: como um tipo de conhecimento gera o outro. In: CAVALCANTI, M.; MOITA LOPES, L. P. (orgs.). Letramentos como práticas sociais. no prelo.

MOLL, L. C. Literacy research in community and classrooms: a sociocultural approach. In: RUDDELL, B., RUDDELL, M. R.; SINGER, H. (eds.). Theoretical models and processes of reading. New York: International Reading Association, Inc, 1994.

SIGNORINI, I. A letra dá vida mas também pode matar: os sem leitura diante da escrita. Leitura: teoria e prática, 24, 1994a. P. 22-27. 
. 'Esclarecer o ignorante': a concepção escolarizada do acesso ao mundo da escrita. ESP, 15 ( 1 \& 2), 1994b. P. 163-171.

SOARES, M. B. Letramento: um tema em três gêneros. Belo Horizonte: Autêntica, 2004.

STREET, B. Literacy in theory and practice. Cambridge: Cambridge University Press, 1993.

Social literacies: critical approach to literacy in development, ethnography and education. London: Longman, 1995.

TURKLE, S. Parallel lives: working on identity in virtual space. In: GRODIN, D.; LINDOLF, T. R. (eds.). Constructing the self in a mediated world. London: Sage, 1996. 